Meta

Journal des tradlucteurs

Translators' Journal

\title{
Décisions de la Commission de terminologie de l'OLF
}

\section{Robert Dubuc}

Volume 24, numéro 3, septembre 1979

URI : https://id.erudit.org/iderudit/002610ar

DOI : https://doi.org/10.7202/002610ar

Aller au sommaire du numéro

Éditeur(s)

Les Presses de l'Université de Montréal

\section{ISSN}

0026-0452 (imprimé)

1492-1421 (numérique)

Découvrir la revue

Citer ce document

Dubuc, R. (1979). Décisions de la Commission de terminologie de l'OLF. Meta, 24(3), 349-354. https://doi.org/10.7202/002610ar d'utilisation que vous pouvez consulter en ligne.

https://apropos.erudit.org/fr/usagers/politique-dutilisation/ 


\section{ILACCTIUALIITIÍE}

\section{DÉCISIONS DE LA COMMISSION DE TERMINOLOGIE DE L'OLF}

La Commission de terminologie de l'Office de la langue française a publié dans la Gazette officielle du Québec un premier décret de normalisation portant sur la nomenclature des boissons gazeuses. D'abord l'Office réserve l'appellation soda à toutes les boissons gazeuses couramment appelées liqueurs. Les termes liqueur et bière sont strictement réservés aux produits alcoolisés. Désormais les appellations suivantes seront d'emploi obligatoire dans l'étiquetage des boissons gazeuses : Amer (au citron) (bitter lemon), soda mousse (cream soda), soda (au) gingembre (ginger ale), soda (à l') épinette, (spruce beer), soda piquant au gingembre, soda gingembre piquant (ginger beer), soda (à l') orange (orange soda), soda racinette, racinette (root beer), soda hypocalorique (low calories soda), boissons gazeuses, sodas (soft drinks), soda tonique (tonic water), eau gazéifiée, soda (soda water), bière (à la) pression (draft beer), boisson/soda de régime (diet soda). Le décret précise en outre les sens de limonade (boisson gazéifiée, acidulée à base de matières aromatiques en provenance du citron), d'orangeade (non gazeuse) et de nectar (boisson faite d'un jus de fruit pulpeux additionné d'eau).

La Commission a en outre recommandé sans normaliser, l'emploi du terme cellulose pour traduire le terme anglais fibers dans le domaine de l'alimentation; dans le domaine sportif, elle a recommandé de réserver le mot canoé et ses dérivés au vocabulaire de la compétition sportive et d'utiliser le mot canot 
pour désigner l'embarcation légère de type amérindien utilisée comme embarcation de plaisance. La Commission a de plus recommandé de donner aux termes pagaie et aviron le sens consacré par la terminologie sportive internationale.

Pagaie (n. f.) Rame utilisée pour la propulsion des canoés canadiens (pagaie simple) et les kayaks (pagaie double).

Aviron (n. m.) Rame légère, à long manche, des embarcations sportives.

La Commission a normalisé l'emploi du mot pesticide comme terme générique recouvrant à la fois les insecticides, les fongicides, les rodenticides.

Le mot ville remplacera désormais le mot cité pour désigner les agglomérations urbaines importantes.

Dans le domaine de l'alimentation, la patisserie appelée en anglais brownie portera le nom de carré au chocolat.

Enfin la Commission a décrété l'emploi obligatoire des accents et autres signes diacritiques dans les textes composés en majuscules.

ROBERT DUBUC 